\title{
EVALUATION OF THE COMBUSTION PROCESS OF COFFEE HUSK SAMPLES IN A DROP TUBE FURNACE (DTF)
}

\begin{abstract}
G. Cruz $^{\mathrm{a}, \mathrm{b}}$,
and P. M. Crnkovic ${ }^{\mathrm{a}}$

${ }^{\mathrm{a} U n i v e r s i t y ~ o f ~ S a ̃ o ~ P a u l o ~}$

Engineering School of São Carlos

Department of Mechanical Engineering

Thermal Engineering and Fluids Laboratory

Bairro Parque Arnold Schimidt

CEP: 13566-590, São Carlos, São Paulo, Brazil

glaubercruz@gmail.com

${ }^{\mathrm{b}}$ Ceuma University

Coordination of Civil Engineering

Bairro Renascença II

CEP: 65067-351, São Luís, Maranhão, Brazil

\section{ABSTRACT}

Thermal conversion processes that use coffee husk are an alternative to solve the environmental problems of disposal and waste burning in open places and avoid greenhouse gases emissions. The present study evaluates in natura coffee husk samples and residues obtained from a combustion process in a Drop Tube Furnace (DTF). Such an evaluation consists in understanding the efficiency of the burning process, therefore the activation energies $\left(E_{a}\right)$ of the combustion process for both samples were determined. The isoconversional kinetic method (Model Free Kinetics) was used for the determination of the $E_{a}$ values of the samples. The $E_{a}$ values of the main stages of the combustion process (devolatilization and carbonization) for both samples were compared. Thermogravimetric (TG) and Derivative Thermogravimetric (DTG) data at five heating rates (10, 15, 20, 25 and 30 ${ }^{\circ} \mathrm{C} \min ^{-1}$ ) were used for the determination of hemicellulose, cellulose and residual lignin. SEM (Scanning Electronic Microscopy) images and EDS (Energy Dispersive Spectroscopy) analysis were applied as complementary techniques in the combustion process. The results show that for both samples the $E_{a}$ values were higher for the carbonization step than for devolatilization. The $E_{a}$ values for the stages of devolatilization and carbonization for the residues were 33 and $15 \%$ lower than those for the in natura coffee husk samples. The lower $E_{a}$ values in both steps for the residues are indicative of a reduction in the complexity of the reaction mechanism, which can be a parameter for the evaluation of the biomass combustion process. According to the SEM images, the residues showed exploded surfaces caused by the combustion process, whereas in the in natura samples a denser and robust structure was observed. The ash formed after the combustion process in the thermobalance was also evaluated by SEM and EDS analyses and showed a more homogenous structure with tiny particles in comparison with the in natura coffee husk samples. The EDS analysis confirmed the presence of precursor elements in the samples, such as potassium and other inorganic materials, which were intensified after the combustion process.
\end{abstract}

Received: September 05, 2015

Revised: October 05, 2015

Accepted: November 06, 2015
Keywords: biomass, combustion, thermal analysis, morphology, kinetic method

\section{NOMENCLATURE}

$\mathrm{E}_{\mathrm{a}} \quad$ activation energy, $\mathrm{kJ} \mathrm{mol}^{-1}$

A pre-exponential factor, $\mathrm{s}^{-1}$

$\mathrm{R}$ universal gas constant, $\mathrm{J} \mathrm{mol}^{-1} \mathrm{~K}^{-1}$

$\mathrm{k}$ constant of reaction rate, $\mathrm{s}^{-1}$

$\mathrm{T}$ temperature, $\mathrm{K}$

$\mathrm{m} \quad$ local sample mass, $\mathrm{mg}$

$f(\alpha)$ reaction model function

$\mathrm{t}$ time, $\mathrm{s}$

$\mathrm{Al}$ aluminum

Ca calcium

$\mathrm{Cl}$ chlorine

$\begin{array}{ll}\mathrm{Fe} & \text { iron } \\ \mathrm{K} & \text { potassium } \\ \mathrm{Mg} & \text { magnesium } \\ \mathrm{Na} & \text { sodium } \\ \mathrm{P} & \text { phosphorus } \\ \mathrm{S} & \text { sulphur } \\ \mathrm{Si} & \text { silicon }\end{array}$

\section{Greek symbols}

$\alpha \quad$ conversion degree, $\%$

$\beta \quad$ heating rate, ${ }^{\circ} \mathrm{C} \mathrm{min}^{-1}$ 


\section{Subscripts}

$\begin{array}{ll}\text { a } & \text { activation energy } \\ 0 & \text { initial } \\ \alpha & \text { conversion degree } \\ \infty & \text { final }\end{array}$

\section{INTRODUCTION}

Among several agricultural cultures in Brazil, coffee has been characterized by its large-scale production. Brazil is the largest consumer and producer worldwide and its contribution to the worldwide scenario is approximately 30\% (Orsini et al., 2011).

The high quality of the Brazilian coffee has added value to the product and increased on average $45 \%$ its consumption by the domestic market over the past 10 years. The other 55\% of the Brazilian coffee production are commercialized by the international market (http://www.abic.com.br. Acessed: 28.08.15).

$55 \%$ of the global coffee productions are grains (dried fruits) and the remaining 45\% are considered wastes. A good use of the residues generated by coffee crops contributes towards mitigating the negative aspects of the gaseous emissions to the environment and creates new energy sources for the country (Venturim, 2002).

Several materials, such as harvest residues and energy crops or even the leftovers of processed products have been discarded in rural environments. These materials negatively contribute to pollution and degradation of soil and water and facilitate the proliferation of diseases (Orsini et al., 2011; Teng et al., 1997).

An alternative to avoid the burning of agricultural residues in fields, which causes emissions of pollutant gases into the atmosphere, is to use them as fuel feedstock in thermal conversion processes, such as biomass combustion for energy production. The Brazilian production of coffee still generates a large amount of residues, which could be utilized for the generation of energy. Although the coffee husks are used by farmers as fertilizers or to heat furnaces for drying beans, two million tons per year still remain and are discarded in rural areas (Orsini, 2012).

Direct combustion is the most common form of thermal biomass conversion for the generation of energy. Other conversion processes, as oxy-fuel combustion, gasification and pyrolysis are promising technologies (Foletto et al., 2005). However, the knowledge on the thermal behavior of these conversion processes is limited and there is no sufficient information on the use of oxidative atmospheres, which are essential to the development and optimization of technological processes.

The combustion process of biomass comprises its burnout in an environment rich in oxygen or air, in which types and properties of biomass fuel, particles size, air flow rate and fuel moisture are considered. Such features directly affect the combustion, as well as the reaction rates, and generation and transfer of heat (Zhao et al., 2012; Senneca, 2007). The biomass combustion is a highly exothermic process that involves a series of successive chemical reactions between the biomass fuel and the oxidizing agent for the production of heat and energy. Several biomasses can be used as appropriate fuel feedstock in many thermal conversion systems (Kok and Özgür, 2013).

The knowledge on the kinetic behavior of the biomass thermal degradation steps is an important parameter for the modeling of both combustion processes and reactor design (Poletto et al., 2012; Moltó et al., 2012). Determining the kinetic parameters of the biomass thermal decomposition is crucial for an accurate prediction of its behavior under different conditions. Several studies have reported different kinetic methods to describe the biomass thermal degradation (Kok and Özgür, 2013; Poletto et al., 2012; Wilson et al., 2011; Harun and Afzal, 2010; Shen et al., 2009; Yao et al., 2008; Ramajo-Escalera et al., 2006). The determination of the $E_{a}$ values based on the Arrhenius's equation and using thermogravimetric data has been widely applied for the evaluation of change mechanisms in solid phases.

Based on the scenario presented and using coffee plantation residues, this study investigates the combustion process of coffee husk samples in a Drop Tube Furnace (DTF). Activation energy $\left(E_{a}\right)$ values were obtained by Thermogravimetry (TG) and a mathematical model (Model Free Kinetics) was used as a tool to understand the combustion process. TG experiments were performed under synthetic air atmosphere to simulate conventional combustion. In addition, Scanning Electronic Microscopy (SEM) images and Energy Dispersive Spectroscopy (EDS) analysis were applied for the evaluation of the morphological structure and composition analysis of the coffee husk samples before and after the combustion process.

\section{THEORY}

\section{Determination of the activation energies by Model-Free Kinetics}

The activation energies for the combustion processes of two samples (in natura coffee husk and residues) were obtained using non-isothermal thermogravimetric experiments and Model Free Kinetics.

The Model Free Kinetics method enables the evaluation of the Arrhenius parameters. It is based on isoconversional techniques and calculates the activation energy as a function of conversion $\left(\mathrm{E}_{\mathrm{a}}=\mathrm{f}(\alpha)\right.$ ) (Vyazovkin et. al, 2011; Vyazovkin and Wight, 1999; Vyazovkin and Dollimore, 1996; Vyazovkin, 1997; Vyazovkin and Sbirrazzouli, 
1997). The method is supported on the assumption that:

$$
\frac{\mathrm{d} \alpha}{\mathrm{dt}}=\mathrm{k}(\mathrm{T}) \cdot \mathrm{f}(\alpha)=A \exp \left(-\frac{\mathrm{E}_{\mathrm{a}}}{\mathrm{RT}}\right) \cdot \mathrm{f}(\alpha)
$$

where $T$ is the temperature, $t$ is the time, $f(\alpha)$ is the reaction model, $k(T)$ is the constant of reaction rate, $R$ is the universal gas constant, $A$ is the pre-exponential factor, $E_{a}$ is the activation energy and $(\alpha)$ is the conversion degree.

Conversion degree is defined as $\alpha=\left(m_{0}-m\right) /\left(m_{0}-\right.$ $\mathrm{m}_{\infty}$ ), where $m$ is the local sample mass that varies with time, $m_{0}$ is the initial sample mass and $m_{\infty}$ is the final sample mass. For simple reactions, the function of conversion, $f(\alpha)$, can be determined, but for complex reactions it is generally unknown (Vyazovkin et. al, 2011).

There is a temporal dependence on nonisothermal conditions, which can be eliminated dividing $f(\alpha)$ by the heating rate $\beta=d T / d t$. After rearranging Eq. (1) one obtains:

$$
\frac{1}{f(\alpha)} \mathrm{d} \alpha=\frac{\mathrm{A}}{\beta} \exp \left(-\frac{\mathrm{E}_{\mathrm{a}}}{\mathrm{RT}}\right) \mathrm{dT}
$$

Integrating Eq. (2) up to the conversion at the local temperature, one has:

$$
\int_{0}^{\alpha} \frac{1}{f(\alpha)} d \alpha=g(\alpha)=\frac{A}{\beta} \int_{T_{0}}^{T} \exp \left(-\frac{E_{a}}{R T}\right) d T
$$

Provided that $\mathrm{E}_{\mathrm{a}} / 2 \mathrm{RT}>>1$, the temperature integral of the right hand side can be approximated by

$$
\int_{\mathrm{T}_{0}}^{\mathrm{T}} \exp \left(-\frac{\mathrm{E}_{\mathrm{a}}}{\mathrm{RT}}\right) \mathrm{dT} \approx \frac{\mathrm{R}}{\mathrm{E}_{\mathrm{a}}} \mathrm{T}^{2} \exp \left(-\frac{\mathrm{E}_{\mathrm{a}}}{\mathrm{RT}}\right)
$$

Inserting Eq. (4) in Eq. (3), rearranging Eq. (3) and taking the logarithm of the generated expression one has:

$$
\ln \left(\frac{\beta}{T_{\alpha}^{2}}\right)=\ln \left[\frac{\mathrm{RA}}{\mathrm{E}_{\mathrm{a}} \mathrm{g}(\alpha)}\right]-\frac{\mathrm{E}_{\alpha}}{\mathrm{R}} \frac{1}{\mathrm{~T}_{\alpha}}
$$

where subscript $\alpha$ represents the values related to a given conversion degree. The activation energies can be obtained graphically by plotting $\ln \left(\beta / \mathrm{T}^{2}\right)$ versus $1 / \mathrm{T}$.

\section{EXPERIMENTS}

\section{Samples}

Two samples were evaluated: in natura coffee husk and the residues formed after the combustion process. The in natura coffee husk (Coffea arabica L.) originated from São Paulo State - Southeast region was provided by a group of research on Thermal Processes and Environmental Engineering (PTEA) from the Mechanical Engineering Faculty (FEM) at University of Campinas (Unicamp). Physical-chemical characteristics of the in natura samples were determined and are presented in other previous studies of our research group (Pécora et al., 2014; Cruz and Crnkovic, 2015).

The in natura samples underwent pretreatments that consisted in washing in running water for the removal of impurities, grinding in a laboratory knives mill for reducing the particles size and subsequent sieving for the separation in the required granulometric range. Particles of $0.151 \mathrm{~mm}$ average size were used for all the samples.

\section{Combustion in a Drop Tube Furnace (DTF)}

A Drop Tube Furnace (DTF) electrically heated (3.5 kVA maximum power) was used for the biomass combustion process. The basic dimensions of the experimental apparatus are $60 \mathrm{~mm}$ outer diameter, $400 \mathrm{~mm}$ uniform zone and $200 \mathrm{~mm}$ heated zone. The particles were introduced into the reactor by a vibratory feeding system controlled by amplitude (8\% power at $60 \mathrm{w})$ and frequency $(110 \mathrm{~Hz})$. The sample mass used was $6.0 \pm 0.5 \mathrm{~g}$ for a 10 -minute experiment. An air primary flow rate of $4 \mathrm{~L} \mathrm{~min}^{-1}$ with $20 \%$ oxygen concentration was applied so as to keep the particles in suspension during the combustion process in DTF. After burning at $950{ }^{\circ} \mathrm{C}$, the ash and residue samples were collected for evaluation by TGA, SEM and EDS analyses.

\section{Thermal Analysis (TG/ DTG curves)}

TG/DTG non-isothermal experiments were performed in a Shimadzu thermogravimetric analyzer, TGA-50H model, for the obtaining of experimental data. The three thermal degradation steps related to hemicellulose, cellulose and residual lignin were evaluated. The conditions used were oxidizing atmosphere (synthetic air) and dynamic flow rate of $100 \mathrm{~mL} \mathrm{~min}^{-1}$. Five heating rates $(10,15,20,25$ and $30{ }^{\circ} \mathrm{C} \mathrm{min}^{-1}$ ) from room temperature up to $700{ }^{\circ} \mathrm{C}$ were used for the experiments. The samples masses were $10.0 \pm 0.5 \mathrm{mg}$ in an alumina crucible. The tests were performed in duplicate and the average values and standard deviations were considered (Table 1).

The activation energies $\left(E_{a}\right)$ versus conversion degree $(\alpha)$ curves of the thermal degradation steps for hemicellulose ( $1^{\text {st }}$ step), cellulose ( $2^{\text {nd }}$ step) and lignin ( $3^{\text {rd }}$ step) were obtained by Model Free Kinetics. Each thermal degradation step was based on the peak separation method of the DTG curves (Vyazovkin et al., 2011). Figure 1 show the TG/ DTG curves for the sugarcane bagasse sample in $\mathrm{N}_{2} / \mathrm{O}_{2}$ atmosphere used 
to explain such separation method.

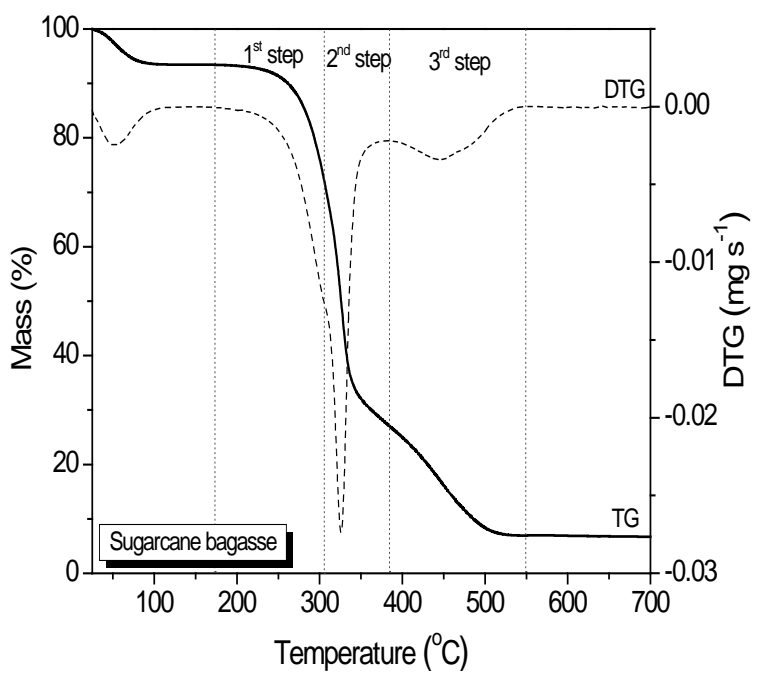

Figure 1. TG/DTG curves for the sugarcane bagasse sample under synthetic air atmosphere at $10^{\circ} \mathrm{C} \mathrm{min}{ }^{-1}$, showing the three thermal degradation steps.

\section{Scanning Electronic Microscopy (SEM images)}

The morphological analysis of the in natura, residues and ash coffee husk samples was conducted under a Scanning Electron Microscope, LEO 440 model of 1,000 times amplitude. Before being placed under the microscope, the samples were deposited on an aluminum support and then metalized in gold bath.

\section{Energy Dispersive Spectroscopy (EDS analysis)}

The in natura coffee husk samples, residues and ash were prepared by sintering for a best adherence on the surface of the aluminum support for the EDS analysis, which was also performed under a Scanning Electron Microscope, LEO 440 model. No metallization type (gold or graphite bath) was used for this analysis, as it may hide or show regions of some elements (organic and inorganic) more common in lignocellulosic materials.

\section{RESULTS AND DISCUSSION}

\section{Thermal Analysis (TG/ DTG curves)}

The TG curves (Figs. 2a and b) show the mass loss events for the in natura coffee husk and residue samples, respectively, at 5 heating rates under synthetic air atmosphere. Both samples exhibited a similar behavior. As the heating rate increased, there was a displacement of the TG curves to higher temperatures and lower times (Moltó et al., 2006). This thermal behavior provided information on the reliability of the thermogravimetric data for the application of the kinetic method - Model Free Kinetics.
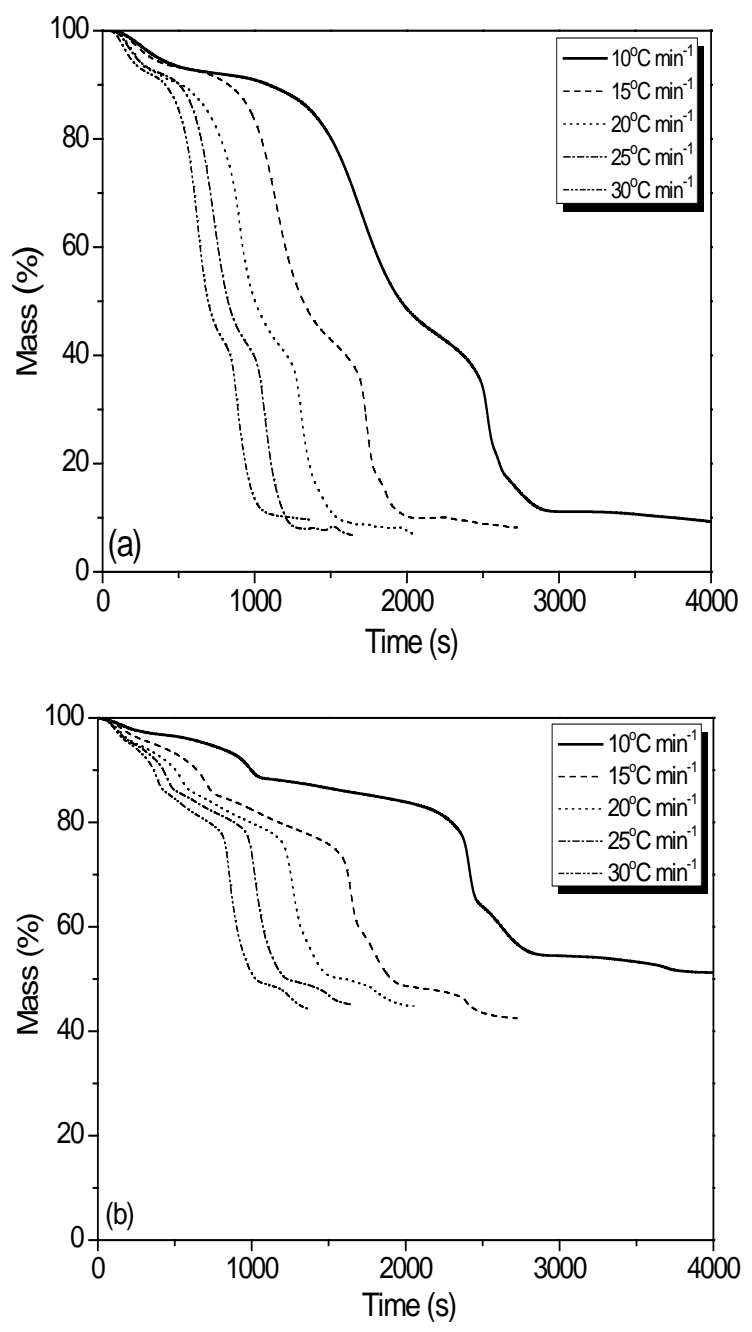

Figure 2. TG curves for the coffee husk samples at five heating rates under synthetic air atmosphere:

(a) in natura and (b) residues.

The TG/ DTG curves (Figs. 3a and b) for the in natura coffee husk and residue samples show the 3 thermal degradation steps under synthetic air atmosphere and related to (I) moisture evaporation, (II) hemicelluloses and cellulose decomposition, and (III) lignin decomposition. The final mass corresponds to the ash content.

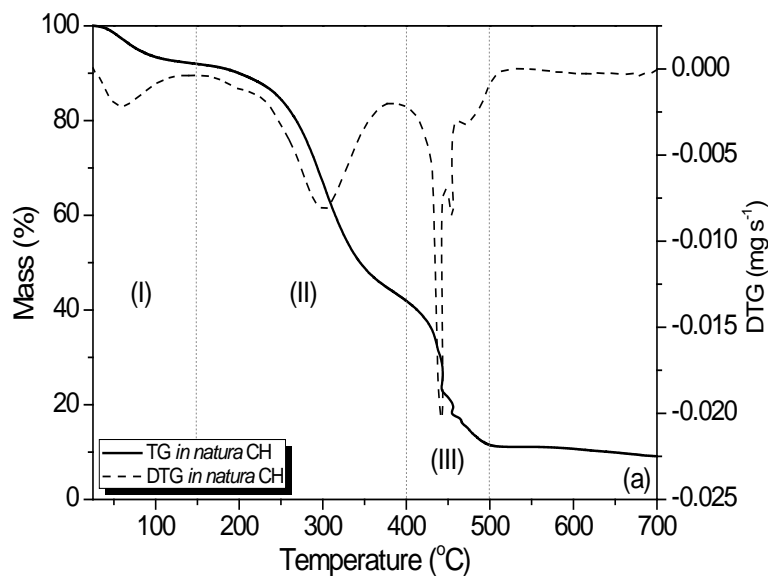




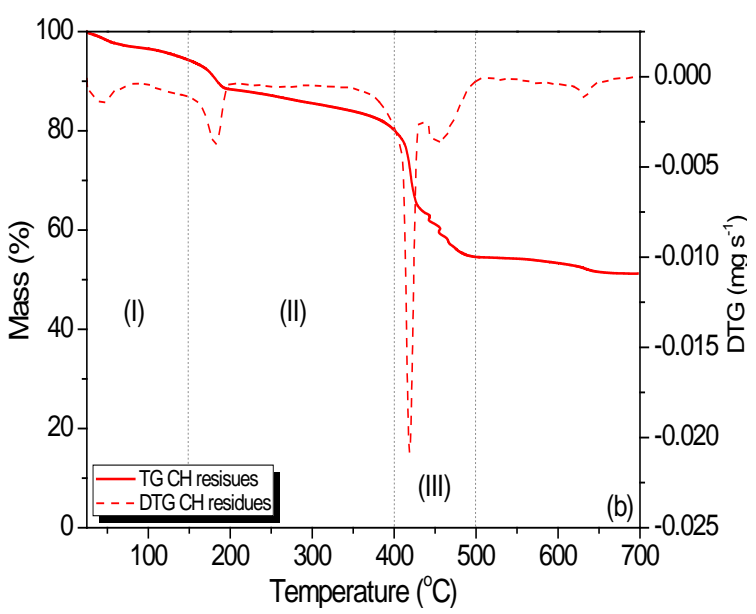

Figure 3. TG/ DTG thermograms for the coffee husk samples at $10^{\circ} \mathrm{C} \mathrm{min}^{-1}$ under synthetic air atmosphere: (a) in natura and (b) residues.

The decomposition of each component for two samples showed well-defined temperature ranges. In the moisture release step (I region) in the residue samples, there was a lower mass loss of $62 \%$ in comparison with the in natura coffee husk samples, because the residues underwent a thermal pretreatment in DTF and part of their moisture was eliminated in the combustion process.

According to the DTG curves, in the II region of the in natura samples under combustion atmosphere, hemicellulose and cellulose exhibited a decomposition temperature peak at $\approx 300{ }^{\circ} \mathrm{C}$. However, for the residues this temperature was achieved at approximately $180^{\circ} \mathrm{C}$. This displacement to lower temperatures for the coffee husk residues can be explained by the breakdown of the lignocellulosic matrix and volatiles release, which caused a progress in the reaction rate (Jenkins et al., 1998).

For both in natura coffee husk and residue samples a maximum combustion rate $\left(\approx 0.020 \mathrm{mg} \mathrm{s}^{-1}\right)$ with maximum temperature peaks at 442 and $419{ }^{\circ} \mathrm{C}$, respectively, was also observed, which indicates that in the III region between 400 and $500{ }^{\circ} \mathrm{C}$ there occurred the onset of the char particles combustion and first clues of the ash formation are provided. This same behavior was observed by Haykiri-Açma (2003) for cone pine and sunflower shell samples.

The oxygen present in the atmosphere strongly influences the volatile release and the combustion stage and benefits ignition (Kumar et al., 2009). For both samples the residual lignin decomposition achieved its maximum degradation temperature under combustion atmosphere at approximately $460{ }^{\circ} \mathrm{C}$.

The temperatures for the maximum combustion rates to take place are significantly affected by the higher alkaline metal content present in the biofuels (Williams et al., 2012). Significant differences were also observed in the ignition temperatures for both samples. For the in natura samples, the ignition temperature ranged between 130 and $150{ }^{\circ} \mathrm{C}$, whereas for coffee husk residues it varied from 90 to $98{ }^{\circ} \mathrm{C}$. This difference may be related to the high consumption of lignocellulosic material (large mass loss) by its transformation into gases (mainly $\mathrm{CO}_{2}$ and $\mathrm{H}_{2} \mathrm{O}$ vapour) and solid wastes after a combustion process (Fernández et al., 2012), in this case in a DTF.

In the IV region, the final carbonization process occurs and the residual mass corresponds to the ash content. For the coffee husk samples, in particular, this ash formed is composed of inorganic materials, predominantly potassium and its oxides. In this study, for all samples, the $\mathrm{K}$ content ranged from 4 to $36 \%$. The inorganic materials are precursors of several problems during thermal processes, such as agglomeration, slagging, fouling in feeding systems, damage to the heat transfer and energy generation in many real thermal processes.

Table 1 shows the percentages of mass loss (contents of moisture, hemicellulose, cellulose, lignin and ash) for the in natura coffee husk and residue samples along their thermal degradation processes. The values were obtained by thermal analysis under synthetic air atmosphere.

Table 1. Mass loss percentages (\%) under synthetic air atmosphere for the thermal degradation steps.

\begin{tabular}{|l|l|l|}
\hline Coffee husk samples & in natura & residues \\
\hline moisture & $8.2 \pm 0.3$ & $3.1 \pm 0.3$ \\
\hline hemicellulose & $50.2 \pm 2.0$ & $9.0 \pm 0.0$ \\
\hline cellulose & $23.3 \pm 1.6$ & $24.4 \pm 0.4$ \\
\hline residual lignin & $10.0 \pm 1.1$ & $12.2 \pm 0.2$ \\
\hline ash & $8.3 \pm 2.5$ & $51.3 \pm 0.2$ \\
\hline
\end{tabular}

Regarding the moisture release, the mass loss for the residues showed a decrease of $\approx 62 \%$ in comparison to the in natura samples. The moisture content associated with biomass fibers is very difficult to be removed due to the hydrophilic nature of lignocellulosic materials (Sasmal et al., 2012).

The amount of hemicelluloses for the residues showed a decrease of $\approx 82 \%$. Variations of 5 and $18 \%$ were detected for the thermal degradation of cellulose and residual lignin, respectively. These compounds exhibit deeper layers on the cell wall and a higher thermal stability (Yang et al., 2007).

In general, the biomasses show higher volatile materials, of the order of 70 to $80 \%$. For the in natura samples, the volatile material content was approximately 74\% (García et al., 2012; Saenger et al., 2001). The coffee husk residues showed approximately $33 \%$ of volatiles released, probably due to the partial release of these compounds by the combustion process.

The residues exhibited a high ash amount, which corresponds to thermal decomposition of organic and inorganic materials in DTF.

\section{Kinetic Study (Model Free Kinetics)}


A kinetic model for the thermal decomposition of a solid biofuel was adopted for the description of the conversion process of in natura coffee husk and residue samples in the volatiles release and char formation (Shuangning et al., 2006). Isoconversional methods, as Model Free Kinetics estimate the $E_{a}$ values as a function of the conversion degree $(\alpha)$, without the need for choosing a model or a reaction order. A basic assumption of this method is that the reaction rate for a constant extension of the conversion degree $(\alpha)$ depends only on the temperature (Ramajo-Escalera et al., 2006). The authors divided the conversion degree $(\alpha)$ into four regions to better explain the $\mathrm{E}_{\mathrm{a}}$ behavior: (I) evaporation, (II) devolatilization, (III) carbonization and (IV) ash formation, with determined temperature ranges.

The $E_{a}$ versus $(\alpha)$ curves for the thermal degradation of hemicelluloses and cellulose ( $1^{\text {st }}$ step) for the in natura coffee husk samples (Fig. 4a) showed a heterogeneous behavior, $i$. e. they ranged from 2 to $175 \mathrm{~kJ} \mathrm{~mol}^{-1}$. Such a behavior can be explained by changes in the mechanism during the thermal decomposition and the complexity of the samples. However, a more stable behavior was observed for the residues (Fig. 4b). In this step devolatilization (II), which covers 15 to $60 \%$ of the conversion process, is the dominant mechanism of mass loss. The biomasses release a large amount of volatiles at temperatures below $400{ }^{\circ} \mathrm{C}$. The devolatilization occurs faster than the carbonization, as the former requires a higher $\mathrm{E}_{\mathrm{a}}$ (García et al., 2012; Shen et al., 2009; Nassar et al., 1996).

In the $2^{\text {st }}$ step, both samples (in natura coffee husk and residues) showed a similar behavior and the $\mathrm{E}_{\mathrm{a}}$ ranged from 91 to $196 \mathrm{~kJ} \mathrm{~mol}^{-1}$ and from 83 to 172 $\mathrm{kJ} \mathrm{mol}^{-1}$, respectively, which can be associated with the thermal decomposition of cellulosic compounds of high thermal stability (Carrier et al., 2011; Yang et al., 2007).

In the III region, known as carbonization step, which corresponds to 60 to $70 \%$ of the conversion process, between 400 and $500{ }^{\circ} \mathrm{C}$, there occurs the onset of the combustion of the char particles (Saenger et al., 2001). In the $3^{\text {rd }}$ step, no significant variation in $\mathrm{E}_{\mathrm{a}}$ was observed.

In the IV region, 70 to $95 \%$ of the combustion process was concluded. This region is characterized by the burnout of remaining materials in the samples and full formation of ash.

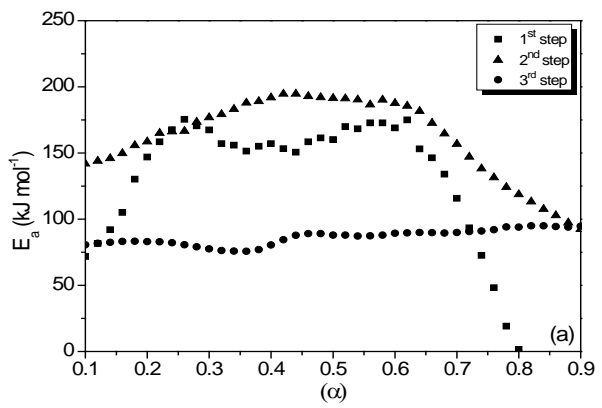



$(\alpha)$

Figure 4. Activation energies $\left(E_{a}\right)$ versus conversion degree $(\alpha)$ under synthetic air atmosphere for the coffee husk samples: (a) in natura and (b) residues.

Table 2 shows the $\mathrm{E}_{\mathrm{a}}$ values for both in natura coffee husk and residue samples.

Table 2. Activation energy $\left(E_{a}\right)$ values $\left(\mathrm{kJ} \mathrm{mol}^{-1}\right)$ for the thermal degradation steps of both coffee husk samples under synthetic air atmosphere.

\begin{tabular}{|l|l|l|l|c|}
\hline $\begin{array}{l}\text { Coffee husk } \\
\text { samples }\end{array}$ & $1^{\text {st }}$ step & $2^{\text {nd }}$ step & $3^{\text {rd }}$ step & $4^{\text {th }}$ step \\
\hline in natura & $98 \pm 77$ & $153 \pm 36$ & $87 \pm 7$ & - \\
\hline residues & $66 \pm 16$ & $130 \pm 35$ & $101 \pm 10$ & $32 \pm 21$ \\
\hline
\end{tabular}

The $E_{a}$ values in the $1^{\text {st }}$ and $2^{\text {nd }}$ steps for the residue samples showed decreases of 33 and 15\%, respectively, in comparison with in natura samples. Such lower values are possibly associated with the decrease in the complexity of the thermal degradation reactions of hemicellulose and cellulose, which may have been affected by an increase in the temperature during the combustion process in a DTF and, consequently, the disruption of the lignocellulosic structure (Teng et al., 1997).

In the $3^{\text {rd }}$ step a $16 \%$ increase in the $\mathrm{E}_{\mathrm{a}}$ value for the residue samples was observed. This increase can be indicative of the variation in the mechanism of the chemical reactions in thermal processes (Saddawi et al., 2010; Ledakowicz and Stolarek, 2002).

The coffee husk residues showed a $4^{\text {th }}$ degradation step with a lower $E_{\mathrm{a}}$ value $\left(\approx 32 \mathrm{~kJ} \mathrm{~mol}^{-}\right.$ ${ }^{1}$ ), possibly attributed to the oxidation of inorganic materials not burned at temperatures below $700{ }^{\circ} \mathrm{C}$, which may lead to the formation of corrosive gaseous species, such as potassium, sulphur and chlorine (Saidur et al., 2011; Saenger et al., 2001).

\section{Scanning Electronic Microscopy (SEM images)}

Figures $5 a$ to $5 c$ show the SEM micrographies for the in natura, residues and ash coffee husk samples, respectively. The biomass samples used showed quite different morphological characteristics.

For the in natura samples (Fig. 5a), the surface structure is denser and robust and contains large elongated grains, non-homogeneous surfaces, well- 
defined grain contours, a thicker morphological structure with a slight elevation, roughness, and cracks surfaces. The residues (Fig. 5b) exhibited a non-uniform structure, several cracks emerging on the surface and holes, possibly due to the volatile materials released during the combustion process. Such features are also typical of severe torrefaction processes $\approx 300{ }^{\circ} \mathrm{C}$ (Biagini et al., 2005). In general, the studied samples seem to exhibit some macroporosity. Cetin et al. (2004) reported that at low heating rates $\left(20{ }^{\circ} \mathrm{C} \mathrm{s} \mathrm{s}^{-1}\right)$, the porosity of biomasses enables high volatile releases with no major morphological changes.

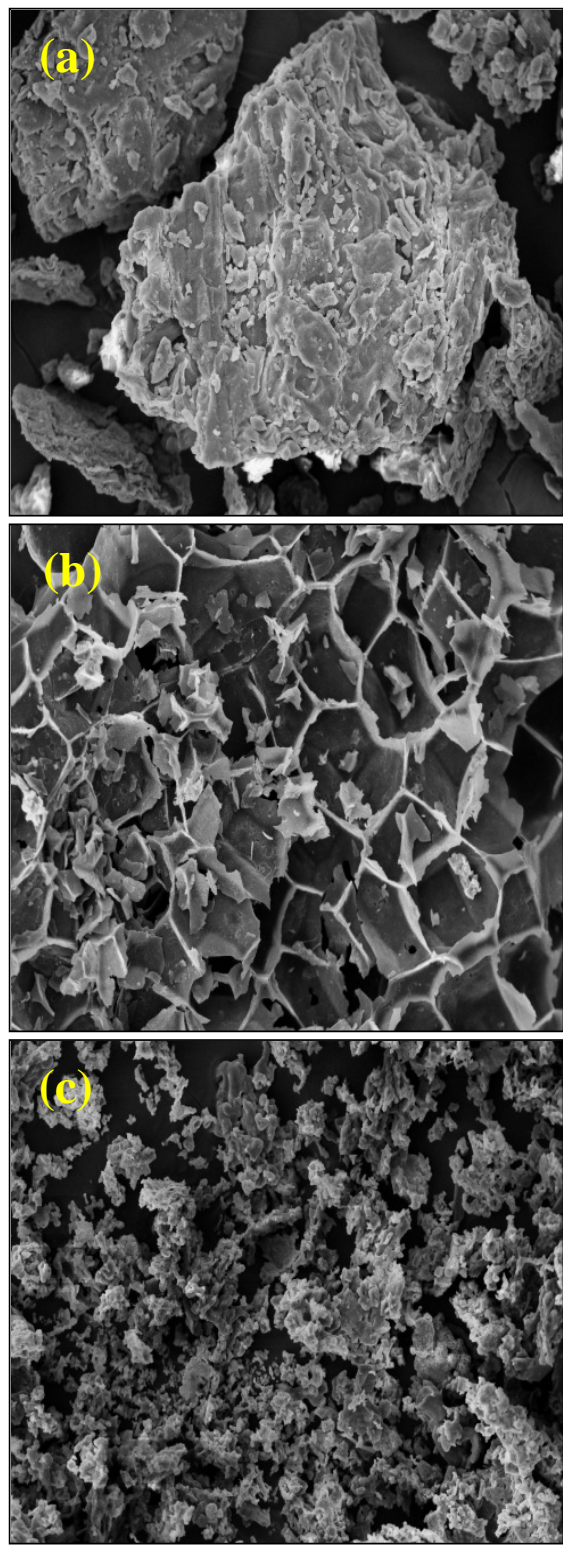

Figure 5. SEM micrographies of the coffee husk samples with magnitude of 1,000 times: (a) in natura, (b) residues and (c) ash.

The ash samples obtained by thermogravimetry (Fig. 5c) confirmed that the combustion process was concluded satisfactorily. A more homogeneous structure (amalgam-type) with tiny particles, probably because of the agglomeration phenomena due to the melting of alkali compounds was observed (Fernández et al., 2012). The inorganic materials contained in the ash, mainly potassium and its oxides, contribute to the agglomerate, slagging, fouling and corrosion in many real thermal processes (Saenger et al., 2001).

\section{Energy Dispersive Spectroscopy (EDS analysis)}

Figure 6 shows the EDS analysis in terms of mass percentage for the in natura, residues and ash coffee husk samples. This technique determined the elemental composition and compared its compositional evolution. The results were obtained from three different points of the samples. The average values and standard deviations are showed in the Fig. below.



Figure 6. EDS analysis of the in natura, residues and ash coffee husk samples.

The in natura samples are formed basically by carbon content $(\approx 47 \%)$ and oxygen $(\approx 48 \%)$. The combination of these two elements confers the biomass a high heating value. Both elements suffered a decrease in the residues of the order of $30 \%$ and $31 \%$, respectively, probably due to the partial combustion and volatile releases.

Regarding the ash samples in comparison with the residues, the carbon content suffered $\mathrm{a} \approx 68 \%$ decrease due to the complete combustion and the oxygen content increased $\approx 26 \%$. Such an increase may be due to either the release of the oxygen contained in the sample or the incorporation of oxygen of the oxidizing atmosphere by the different oxides formation.

Other elements, such as $\mathrm{Mg}, \mathrm{Si}, \mathrm{P}, \mathrm{Cl}, \mathrm{Ca}$ and Fe were also found in smaller amounts in the in natura samples. Chlorine traces that appear in the in natura samples may be due to the use of fertilizers during the growth of the crop. Such an element may cause corrosion problems in the combustion chamber and environmentally unfriendly emissions during the 
combustion process (Fernández et al., 2012).

After the combustion in the DTF, the residue samples showed changes in their composition whereas some trace elements, such as $\mathrm{Mg}, \mathrm{Si}, \mathrm{P}, \mathrm{Cl}$, $\mathrm{Ca}$ and Fe had a slight increase. $\mathrm{Al}$ and $\mathrm{S}$ appear only in the residue samples and ash composition. The presence of some elements, as $\mathrm{P}, \mathrm{Ca}, \mathrm{Al}$ and $\mathrm{Si}$, and their respective oxides in the solid wastes still generates large environmental problems. A deeper study is necessary for the obtaining of information on possible applications of these elements, as for example, their use in industries of concretes or composites (Foletto et al., 2005).

The in natura samples showed a $4 \%$ composition of potassium (K), which is their major constituent among the inorganic materials. It appeared as the main precursor in the ash formation, slagging, agglomeration and fouling in feeding systems (Sanger et al., 2001). After the combustion in $\mathrm{DTF}$, the $\mathrm{K}$ composition increased considerably (530\% and $800 \%$ for residues and ash samples, respectively), probably due to its exposure or intensification at high temperatures $\left(\approx 700^{\circ} \mathrm{C}\right)$.

The EDS analysis was used to identify possible alkalis elements in the ash, such as $\mathrm{Na}, \mathrm{K}, \mathrm{Mg}$ and $\mathrm{Ca}$ (oxides, hydroxides and carbonates of alkaline metals and alkaline earth), which generate slagging. A combustion process that uses residues with a high amount of those elements is environmentally undesirable (Fernández et al., 2012).

\section{CONCLUSIONS}

In this study in natura coffee husk and residue samples were used for an investigation into the efficiency of the combustion process in a Drop Tube Furnace (DTF). The residues of the combustion were also evaluated by TGA, SEM and EDS analyses.

The efficiency of the burning process in the DTF was evaluated by means of TG/ DTG curves. The in natura coffee husk samples were partially carbonized, possibly due to the short residence time or particles agglomeration. DTF can be used in thermal conversion processes and fast pretreatments of biomasses to enhance their intrinsic characteristics.

Regarding the Model Free Kinetics, for the $1^{\text {st }}$ and $2^{\text {nd }}$ steps, the residues showed $\mathrm{E}_{\mathrm{a}}$ values $\approx 33$ and $15 \%$ lower than those of in natura samples. However, for the $3^{\text {rd }}$ step $a \approx 16 \%$ increase was observed. On average, the $E_{a}$ values were lower in residues than in in natura samples, due to the disruption of the lignocellulosic structure after the burning process. The residues showed a $4^{\text {th }}$ step with low $\mathrm{E}_{\mathrm{a}}$ values. In the devolatilization stage, the $E_{a}$ values were lower than those in the carbonization stage. Such characteristics may be indicative of the efficiency of the biomass combustion process in a DTF.

The SEM images of the in natura samples showed a denser and robust structure, elongated grains, roughness, and crack surfaces, whereas the residues exhibited a non-uniform structure and several cracks emerging on the surface by the release of volatiles. The combustion process occurred only on the sample surfaces, which may be indicative of the severe torrefaction process. The ash generated after TG analysis showed a more homogenous structure with tiny particles, probably due to the agglomeration and melting of alkaline compounds.

The EDS analysis identified possible alkaline elements, such as $\mathrm{K}, \mathrm{Mg}$ and $\mathrm{Ca}$, which are main precursors in the ash formation, agglomeration, slagging, and fouling in thermal systems.

\section{ACKNOWLEDGEMENTS}

The authors gratefully acknowledge the funding agencies CAPES (DS00011/07-0) and FAPESP (2012/00639-2) for the financial support and Angela Pregnolato Giampedro for the English language review.

\section{REFERENCES}

Biagini, E., Cioni, M., and Tognotti, L., 2005, Development and Characterization of a Lab-Scale Entrained flow Reactor for Testing Biomass Fuels, Fuel, Vol. 84, No. 12-13, pp. 1524-1534.

Carrier, M., Loppinet-Serani, A., Denux, D., Lasnier, J. M., Ham-Pichavant, F., Cansell, F., and Aymonier, C., 2011, Thermogravimetric Analysis as a new Method to Determine the Lignocellulosic Composition of Biomass, Biomass and Bioenergy, Vol. 35, No. 1, pp. 298-307.

Cetin, E., Moghtaderi, B., Gupta, R., and Wall, T. F., 2004, Influence of Pyrolysis Conditions on the Structure and Gasification Reactivity of Biomass Chars, Fuel, Vol. 83, No. 16, pp. 2139-2150.

Cruz, G., and Crnkovic, P. M., Investigation into the Kinetc Behavior of Biomass Combustion under $\mathrm{N}_{2} / \mathrm{O}_{2}$ and $\mathrm{CO}_{2} / \mathrm{O}_{2}$ Atmospheres, Journal of Thermal Analysis and Calorimetry, Vol. 121, No. 4, pp. 1-9.

Fernández, R. G., García, C. P., Lavín, A. G., and Heras, J. L. B., 2012, Study of main Combustion Characteristics for Biomass Fuels used in Boilers, Fuel Processing Technology, Vol. 103, No. 1, pp. 1626.

Foletto, E. L., Hoffmann, R., Hoffmann, Portugal Jr., U. L., and Janh, S. L., 2005, Applicability of Rice Husk Ash, Quimica Nova, Vol. 28, No. 6, pp. 1055-1060.

García, R., Pizarro, C., Lavín, A. G., and Bueno, J. L., 2012, Characterization of Spanish Biomass Wastes for Energy use, Bioresource Technology, Vol. 103, No. 1, pp. 249-258.

Harun, N. Y., Afzal, and M. T., 2010, Thermal Decomposition Kinetics of Forest Residue, Journal of Applied Science, Vol. 10, No. 12, pp. 1122-1127.

Haykiri-Açma, H., 2003, Combustion Characteristics of Diffent Biomass Materials, Energy 
Conversion and Management, Vol. 44, No. 1, pp. 155-162.

Jenkins, B. M., Baxter, L. L., Miles Jr., T. R., and Miles, T. R., 1998, Combustion Properties of Biomass, Fuel Processing Technology, Vol. 54, pp. 17-46.

Kok, M. V., and Özgür, E., 2013, Thermal Analysis and Kinetics of Biomass Samples, Fuel Processing Technology, Vol. 106, No. 1, pp. 739745.

Kumar, A., Jones, D. D., and Hanna, M. A., 2009, Thermochemical Biomass Gasification: a Review of the Current Status of the Technology, Energies,Vol. 2, No. 1, pp. 556-581.

Ledakowicz, S., and Stolarek, P., 2002, Kinetics of Biomass Thermal Decomposition, Chemical Papper, Vol. 56, No. 6, pp. 378-381.

Moltó, J., Font, R., Conesa, J. A., and MartínGullón, I., 2006, Thermogravimetric Analysis during the Decomposition of Cotton Fabrics in an Inert and Air Environment, Journal of Analalytical Applied Pyrolysis, Vol. 76, No. 1-2, pp. 124-131.

Nassar, M. M., Ashour, E. A., and Wahid, S. S., 1996, Thermal Characteristics of Bagasse, Journal of Applied Polymer Science, Vol. 61, No. 6, pp. 885890.

Orsini, R. R., 2012, Estudo do Aproveitamento do Resíduo da Lavoura Cafeeira como Fonte de Biomassa na Produção de Hidrogênio, Ph.D. Thesis, Universidade de São Paulo, São Paulo, SP, Brazil. (in portuguese)

Orsini, R. R., Filho, E. M., Mercuri, L. P., Matos, J. R., and Carvalho, F. M. S., 2011, Thermoanalytical Study of Inner and Outer Residue of Coffee Harvest, Journal of Thermal Analysis and Calorimetry, Vol. 106, No. 3, pp. 741-745.

Pécora, A. A. B., Ávila, I., Cruz, G., Lima, C., and Crnkovic, P. M., 2014, Prediction of the Combustion Process in Fluidized bed Based on Physical-Chemical Properties of Biomass Particles and their Hydrodynamic Behaviors, Fuel Processing Technology, Vol. 124, No. 1, pp. 188-197.

Poletto, M., Zaterra, A. J., and Santana, R. M. C., 2012, Thermal Decomposition of Wood: Kinetics and Degradation Mechanisms, Bioresource Technology, Vol. 126, No. 1, pp. 7-12.

Ramajo-Escalera, B., Espina, A., García, J. R., Sosa-Arnao, J. H., and Nebra, S. A., 2006, ModelFree Kinetics Applied to Sugarcane Bagasse Combustion, Thermochimica Acta, Vol. 448, No. 2, pp. 111-116.

Saddawi, A., Jones, J. M., Williams, A., and Wójtowicz, M. A., 2010, Kinetics of the Thermal Decomposition of Biomass, Energy and Fuel, Vol. 24, No. 2, pp. 1274-1282.

Saenger, M., Hartge, E. U., Werther, J., Ogada, T., and Siagi, Z., 2001, Combustion of Coffee Husks, Renewable Energy, Vol. 23, No. 1, pp. 103-121.

Saidur, R., Abdelaziz, E. A., Demirbas, A., Hossain, M. S., and Mekhilef, S., 2011, A Review on
Biomass as a Fuel for Boilers, Renewable and Sustainable Energy Sources, Vol. 15, No. 5, pp. 2262-2289.

Sasmal, S., Goud, V. V., and Mohanty, K., 2012, Characterization of Biomasses Available in the Region of North-East India for Production of Biofuels, Biomass and Bioenergy, Vol. 45, No. 1, pp. 212-220.

Senneca, O., 2007, Kinetics of Pyrolysis, Combustion and Gasification of Three Biomass Fuels, Fuel Processing Technology, Vol. 88, No. 1, pp. 87-97.

Shen, D. K., Gu, S., Luo, K. H., Bridgwater, A. V., and Fang, M. X., 2009, Kinetic Study on Thermal Decomposition of Woods in Oxidative Environment, Fuel, Vol. 88, No. 6, pp. 1024-1030.

Shuangning, X., Zhihe, L., Baoming, L., Weiming, Y., and Xueyuan, B., 2006, Devolatilization Characteristics of Biomass at Flash Heating Rate, Fuel, Vol. 85, No. 5, pp. 664-670.

Teng, H., Lin, H. C., and Ho, J. A., 1997, Thermogravimetric Analysis on Global Mass Loss Kinetics of Rice Hulls Pyrolysis, Industrial and Engineering Chemistry Research, Vol. 36, No. 9, pp. 3974-3977.

Venturim, J. B., 2002, Gestão de Resíduos Orgânicos Produzidos por Meio Rural: o Caso do Beneficiamento do Café, Ph. D. Thesis, Universidade Federal de Santa Catarina, Florianópolis, SC, Brazil. (in portuguese)

Vyazovkin, S., Burnham, A. K., Criado, J. M., Pérez-Maqueda, L. A., Popescu, C., and Sbirrazzuoli, N., 2011, ICTAC Kinetics Committee Recommendations for Performing Kinetic Computations on a Thermal Analysis Data, Thermochimica Acta, Vol. 520, No. 1-2, pp. 1-19.

Vyazovkin, S., and Wight, C. A., 1999, ModelFree and Model-Fitting Approaches to Kinetic Analyses of Isothermal and Non-Isothermal Data, Thermochimica Acta, Vol. 340, No. 1, pp. 53-68.

Vyazovkin S., and Dollimore D., 1996, Linear and Nonlinear Procedures in Isoconversional Computations of the Activation Energy of NonIsothermal Reaction in Solids, Journal of Chemical, Information and Computer Sciences, Vol. 36, No. 1, pp. $42-45$.

Vyazovkin, S., 1997, Advanced Isoconversional Method, Journal of Thermal Analysis and Calorimetry, Vol. 49, No. 3, pp. 1493-1499.

Vyazovkin, S., and Sbirrazzuoli, N., 1997, Confidence Intervals for the Activation Energy Estimated by Few Experiments, Analytica Chimica Acta, Vol. 355, No. 2-3, pp. 175-180.

Williams, A., Jones, J. M., Ma, L., and Pourkashanian, M., 2012, Pollutants from the Combustion of Solid Biomass Fuels, Progress in Energy and Combustion Science, Vol. 38, No. 1, pp. 113-137.

Wilson, L., Yang, W., Blasiak, W., Jonh, G. R., and Mhilu, C. F., 2011, Thermal Characterization of 
Tropical Biomass Feedstocks, Energy Conversion Management, Vol. 52, No. 1, pp. 191-198.

Yang, H., Yan, R., Chen, H., Lee, D. H., and Zheng, C., 2007, Characteristics of Hemicelulose, Cellulose and Lignin Pyrolysis, Fuel, Vol. 86, No. 12-13, pp. 1781-1788.

Yao, F., Wu, Q., Lei, Y., Guo, W., and Xu, Y., 2008, Thermal Decomposition Kinetics of Natural Fibers: Activation Energy with Dynamic Thermogravimetric Analysis, Polymer Degradation and Stability, Vol. 93, No. 1, pp. 90-98.

Zhao, W., Li, Z., Wang, D., Zhu, Q., Sun, R., Meng, B., and Zhao, G., 2008, Combustion Characteristics of Different parts of Corn Straw and NO Formation in a Fixed Bed, Bioresource Technology, Vol. 99, No.8, pp. 2956-2963. 